\title{
Managing Tsunami Risk: Social Context Influences on Preparedness
}

\author{
Douglas Paton \\ School of Psychology, University of Tasmania, Australia
}

Bruce F. Houghton

Geology \& Geophysics, University of Hawaii, United States of America

Chris E. Gregg

Department of Geosciences, East Tennessee State University, United States of America

David Mclvor

School of Psychology, University of Tasmania, Australia

David M. Johnston

Joint Centre for Disaster Research, Massey University/GNS Science, New Zealand

Petra Bürgelt

School of Psychology, Massey University, New Zealand

Penny Larin

Geology \& Geophysics, University of Hawaii, United States of America

Duane A. Gill

Social Science Research Center, Mississippi State University, United States of America

Liesel A. Ritchie

The Evaluation Center, Western Michigan University, United States of America

Steven Meinhold and Jennifer Horan

Political Science, University of North Carolina, United States of America

\begin{abstract}
This article describes the testing of a model that proposes that people's beliefs regarding the effectiveness of hazard preparedness interact with social context factors (community participation, collective efficacy, empowerment and trust) to influence levels of hazard preparedness. Using data obtained from people living in coastal communities in Alaska and Oregon that are susceptible to experiencing tsunami, structural equation modelling analyses confirmed the ability of the model to help account for differences in levels of tsunami preparedness. Analysis revealed that community members and civic agencies influence preparedness in ways that are independent of the information provided per se. The model suggests that, to encourage people to prepare, outreach strategies must (a) encourage community members to discuss tsunami hazard issues and to identify the resources and information they need to deal with the consequences a tsunami would pose for them and (b) ensure that the community-agency relationship is complementary and empowering.
\end{abstract}

Keywords: tsunami, community, empowerment, trust, preparedness

Throughout the world, many coastal communities, especially those around the Pacific Rim, face the threat of experiencing loss and devastation from tsunami. In areas susceptible to experiencing locally generated tsunami in particular, it is important that the knowledge, resources and plans necessary to mitigate the associated risk are developed in advance. In such areas, a key risk management goal is encouraging people to prepare (e.g., putting together an emergency kit containing food, water and essential medicines, developing and practising family

Address for correspondence: Douglas Paton, School of Psychology, University of Tasmania, Launceston TAS 7250, Australia. E-mail: Douglas.Paton@utas.edu.au 
response and evacuation plans) in ways that enhance their safety should a tsunami occur (Horikawa \& Shuto, 1983; Weigel, 2006).

Research into factors influencing hazard preparedness has identified how intra-individual factors such as, for example, coping, self-efficacy and control beliefs influence levels of preparedness (Duval \& Mulilis, 1999; Lindell \& Whitney, 2000; Paton, Smith \& Johnston, 2005; Perry \& Lindell, 2004; 2008). Several investigations have also implicated social context factors as predictors of preparedness (Lindell \& Perry, 2004; Paton et al., 2005: Paton et al., 2008). If its role is to be systematically studied, it is necessary to articulate the specific characteristics of the social context that influence preparedness. Furthermore, for reasons outlined below, it is important to identify how the social context in which people live and work can influence hazard preparedness. Exploring this relationship is the subject of this article. The rationale for the approach adopted here derives from understanding how the meaning people attribute to environmental events is constructed through the interactions they have with others.

Symbolic interactionism (Blumer, 1969) suggests that people actively and constantly interpret stimuli from the environment while interacting with the elements in that environment, and integrate the interpretations through a process of reflection with pre-existing mental models. In this way, people construct the meaning of the things they interact with and then act towards them in ways consistent with these meanings.

How people interpret the world differs from person to person, changes over time, depends on context, and reflects the unique experiences they have accumulated during their lives (Bowers, 1988). The diversity of this experience means that, when people interact with the environment they take different objects into account and interpret and integrate them in different ways (Blumer, 1969). In addition, since individuals constantly assimilate new experiences, their sense of self, their interpretations and their actions constantly evolve over time, with this process defining how people adapt to new conditions (Denzin, 1992).

The ultimate function of this interpretive process is to facilitate people's ability to adapt as well as possible to changes in the environment. However, it is important to accommodate the fact that people's interpretations and actions are always contextual and influenced by the social structures (social context) they encounter in everyday life (Blumer, 1969). These conditions, which can become implicit facets of people's lives, can either constrain or facilitate certain individual interpretations and actions. This applies as much to the actions people take to prepare for hazards as it does to the other domains that comprise people's everyday lives. According to this view, the meaning people attribute to events and the action they take towards these events will be influenced by their experiences within these social structures. It thus becomes important to iden- tify the characteristics of these structures and to articulate the way in which they influence actions.

Decisions to act are thus determined by how people interpret hazard events and related information to render them meaningful to them in the context of experiences, beliefs and expectations that are forged, changed and sustained through their social relationships with family, friends, other community members and civic agencies (Paton, 2006). In the context of the uncertainty associated with hazard events, it is argued that the quality of these interactions will represent an important influence on how people attribute meaning to hazards, their consequences and what could or should be done to mitigate hazard impacts.

This article examines how personal beliefs regarding hazards and their mitigation interact with social context factors to influence levels of hazard preparedness. People's deliberations and their interpretation of hazards, as well as information they receive about them, takes place in the course of interaction with others in the contexts (e.g., work, social, sporting and religious meetings) that make up their everyday lives, rather than in groups specifically convened to address hazard issues. It thus becomes important to consider how normal or mainstream social contexts influence preparedness. This approach informed the selection of the predictor variables used in this study.

The objective was to select variables that captured the relationships and competencies that comprise peoples' everyday experiences (e.g., participation in activities with other members of their community). This approach allowed assessment of the degree to which mainstream aspects of community life influence levels of preparedness for hazard consequences. From a practical perspective, this approach is based on the premise that mainstreaming the development of risk management strategies with other community development activities increases the likelihood that a sustained capacity to adapt to infrequent hazard events will develop (Paton, 2006).

The social context was examined from two perspectives. One involved the relationship between community members. This led to the selection of the variables 'community participation' and 'collective efficacy.' The second concerned the relationship between community members and civic sources of hazard information. This resulted in choosing the 'empowerment' and 'trust' variables. The rationale for these choices is discussed in the next section.

\section{Social Context Influences on Hazard Preparedness}

When faced with uncertainty, people turn to others to help them reduce their uncertainty and help them decide what to do to manage their risk (Marris et al., 1998; Rippl, 2002). These others can be civic agencies (e.g., emergency management), but they can also be family members, neighbours and members of the communities (e.g., workplaces, social and sporting clubs, churches) with whom people interact regularly. 
Consequently, both civic and community sources have the potential to make contributions to interpretative processes. The importance of specifically examining the quality of the relationship between community members and civic agencies derives from the fact that, when examining the preparedness process from a social context perspective, the civic agency (e.g., emergency management) role involves more than their just being providers of information.

Levels of risk acceptance and people's willingness to take responsibility for their own safety is increased, and decisions to take steps to actively manage their risk more likely, if people believe that their relationship with formal agencies is fair and empowering (e.g., agencies are perceived as trustworthy, as acting in the interest of community members) (Lion et al., 2002; Paton \& Bishop, 1996; Poortinga \& Pidgeon, 2004). When this relationship is not perceived as fair, the consequence is a loss of trust in the agency (i.e., the source of information).

Trust influences perception of other's motives, their competence and the credibility of information provided (Earle, 2004; Kee \& Knox, 1970; McAllister, 1995). Trust is thus an important determinant of the quality of any relationship in which information is exchanged, appraised and decisions made. However, the significance of considering trust is further heightened by the important role it plays when people must make decisions under conditions of uncertainty (Earle \& Cvetkovich, 1995; Siegrist \& Cvetkovich, 2000). The infrequent, complex and threatening nature of tsunami hazards means that community members have to deal with considerable risk and uncertainty. As uncertainty increases, so does the importance people attribute to their general trust beliefs about, and their past trust experiences with, the sources of information they turn to or have to rely on (Siegrist \& Cvetkovich, 2000; Paton, 2008). Thus, peoples' willingness to use information to guide their actions will be influenced by the degree to which they trust its source. By representing one way of conceptualising how civic agencies (sources of information) influence how people understand the environmental hazards they are being asked to prepare for, trust plays a pivotal role in the process of influencing how people manage uncertainty. The next issue concerned identifying factors that predict trust.

To select appropriate variables, a model that depicts trust as mediating the relationship between dispositional and structural factors and behaviour (Kee \& Knox, 1970; Mayer et al., 1995) was used to provide the theoretical framework. A fuller description of the rationale for developing a model using this theory can be found in Paton (2008). To test the predictions derived from this theory, it was necessary to first identify variables that could used to operationalise the dispositional and social elements of the theory. A more comprehensive description of the variables used and the items that comprise them can be found in Paton (2007). The rationale for the selection of variables is summarised in the next section.

\section{Dispositional Factors}

An important dispositional factor concerns peoples' assessment of the costs and benefits associated with mitigating hazard consequences (Kee \& Knox, 1970). In the context of examining hazard preparedness, the construct of outcome expectancy (Bennett \& Murphy, 1997) was used examine how cost and benefit beliefs could influence preparing.

Significant hazard events occur infrequently. Consequently, people rarely have any chance to gain first hand experience of either the consequences they may encounter or opportunity to assess the effectiveness of proposed mitigation measures for themselves. Rather, they rely on information from expert sources (e.g., through public education programs) that advise people that if they adopt a particular behaviour the outcome will be increased safety. However, people interpret this information and its recommendations to estimate whether they expect that outcome to occur. It is this interpretive process that is captured by outcome expectancy. This provides one approach to operationalising people's perception of the costs and benefits of preparing for hazardous events.

Negative outcomes expectancy taps into beliefs that hazards are too destructive for personal action to make a difference. It describes a situation in which the costs of action outweigh any benefits of implementing an action. Positive outcome expectancy taps into beliefs that personal preparation can make a difference and add value to one's life. That is, people believe that the potential benefits from acting are greater than the costs of acting.

If people have the necessary information and resources, positive outcome expectancy will predict preparing. If people do not have all the information they require, or need guidance to clarify the uncertainty associated with infrequent, complex hazards, they will seek the necessary information from others. That is, when conceptualising preparedness, it is important to distinguish between a belief that preparing can be effective, and knowing how to enact that belief.

If people need additional information to reduce their uncertainty and guide their actions, it is proposed that people look first to other community members and subsequently to civic agencies. With regard to the former, two community variables, 'community participation' and collective efficacy,' were selected on the grounds of their relationship with how people deal with risk. The first of these was selected to allow assessment of the degree to which people systematically engage in social activities. The second was included to assess the capacity of community members to identify what needs to be done in circum- 
stances in which they are presented with a novel problem and/or have to make decisions under conditions of uncertainty.

\section{Community Characteristics}

Faced with complex and uncertain events, when they do not posses all the information they need themselves, peoples' perception of risk and how they might mitigate it, is influenced by information from others who share their interests and values (Earle, 2004; Lion et al., 2002; Paton \& Bishop, 1996; Poortinga \& Pidgeon, 2004). Because participating in community activities provides access to information from people that are more likely to share one's interests, values and expectations, information from community sources can assist understanding one's circumstances and deciding what to do. Consequently, a measure of 'community participation' developed by Eng and Parker (1994) was included in the model. While participation provides access to a wider pool of knowledge and expertise, deciding how they can deal with unfamiliar circumstances will be a function of people's ability to, for example, identify the hazard consequences and their specific implications for them and where they live and work and identifying what can be done to eliminate or minimise hazard consequences for them. Collective efficacy is a construct that can provide insights into community members' ability to perform these problem-solving tasks.

Collective efficacy describes community members' ability to assess their capabilities and resource needs in relation to challenging tasks, define their goals, develop plans for using resources to achieve goals, and it influences the level of persistence people demonstrate when confronted with complex and challenging tasks (Bandura, 1997; Duncan et al., 2003; Zaccaro, Blair, Peterson, \& Zazanis, 1995). Working out what is required to prepare for the consequences of infrequently occurring hazards such as a tsunami would be one such task. Collective efficacy, using a measure developed by Zaccaro et al., (1995), was used to assess community members' ability to identify the information, resource and planning needs required to advance their preparedness planning. Because collective efficacy can only develop in established communities or groups, it is hypothesised that collective efficacy will mediate the relationship between community participation and empowerment.

Collective efficacy can facilitate community members' ability to decide what needs to be done. However, given the atypical nature of the demands associated with preparing for infrequent natural hazard events, it cannot be assumed that members possess the resources, information and skills required to enact these decisions. Community deliberations could identify new information and resource needs that cannot be met within existing community contexts. Under these circum- stances, when information and resources are required from external sources, preparation will be influenced by the quality of the relationship between community members and the civic sources that are repositories of information about hazards.

\section{The Relationship Between People and Sources of Hazard Information}

While public education programs often assume that people will automatically absorb and use any information from expert sources, this is not always the case. Rather, it is the consistency between the needs and expectations generated by community members and the information and resources received from civic sources that help people construct more accurate estimates of risk, reduces uncertainty, and influences trust (Earle, 2004; Eng \& Parker, 1994; Lion et al., 2004). While levels of collective efficacy will influence the degree to which community members can formulate gaps in knowledge and resource needs, their subsequent ability to act will be a function of the degree to which civic agencies empower community members by providing the resources and information that meet peoples' needs and expectations in ways that facilitate their ability to act by filling these gaps (Paton \& Bishop, 1996; Poortinga \& Pidgeon, 2004). A measure developed by Speer and Peterson (2000) was used to assess empowerment. According to this view, community and agency characteristics (participation, collective efficacy, empowerment) play complementary roles within the preparation process. It is proposed that the degree of complementarity in the community-agency relationship will influence levels of trust in a source of information. A measure of trust developed by Dillon and Phillips (2001) was used to assess this facet of the model. It is argued that trust will mediate the relationship between social context factors and, first, intentions to prepare, then actual preparedness.

Research into the adoption of protective behaviour has consistently identified a role for behavioural intentions as a precursor of actual preparedness in this process (Lindell \& Perry, 2004; Paton et al., 2005; Sheeran, 2002). This measure, which assessed peoples' intention to acquire tsunami information, increase their levels of tsunami preparedness, and contact emergency management agencies to assist the development of their response plans, was drawn from an earlier study (Paton et al., 2005). Consistent with the recommendations of Horikawa and Shuto (1983), the preparedness scale measured peoples' ability to respond promptly to protect themselves in the event of a tsunami. The propositions outlined above can be summarised as a series of hypotheses.

\section{Hypotheses}

The model proposes that preparedness is the outcome of a process that commences with peoples' outcome expectancy beliefs. If people hold negative outcome 


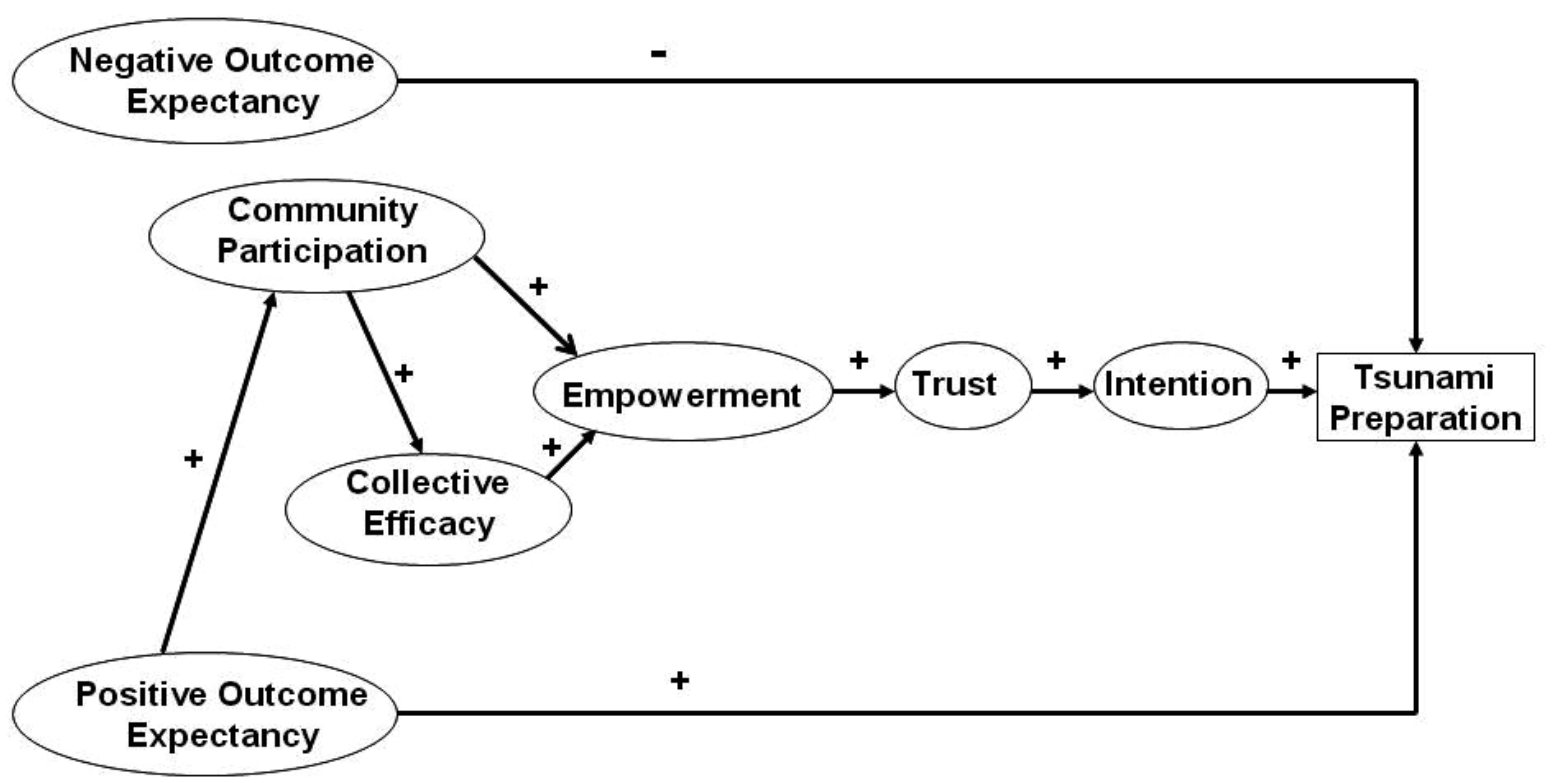

Figure 1

The hypothesised relationships (derived from Paton, 2008).

expectancy beliefs, it is hypothesised that this will reduce the likelihood of preparing. If people hold positive outcome expectancy beliefs, they will either proceed to prepare, or, if lacking the information they require, the relationship between POE and empowerment will be mediated by the structural processes (community participation and collective efficacy) used to articulate members needs and expectations. Next, it is hypothesised that empowerment mediates the relationship between structural factors and trust. Finally, it is hypothesised that trust predicts intentions, with intentions mediating the relationship between trust and preparedness. The hypotheses are depicted in Figure 1.

\section{Methods}

The variables described above were compiled into a questionnaire. In February-April 2007 the questionnaire was administered to residents in coastal communities in Alaska and Oregon that are susceptible to experiencing tsunami. The coastal communities selected face comparable levels of risk from locally generated tsunami (General Accountability Office, 2006). In order to provide a more rigorous assessment of the validity of the model, it was important to test it in different locations. If the predictions are supported by data obtained from different locations, the validity of the model will be increased.

The predictions derived from the relationships hypothesized above were tested and analysed using structural equation modelling. The principle goal of this analysis was to examine whether the proposed model could account for differences in levels of preparedness. Because it can estimate multiple and interrelated dependence relationships simultaneously, structural equation modelling allows sta- tistics to be calculated to test the model as a whole and to show how well the data fit the hypothesised model (Goodness-of Fit). Consequently, structural equation modelling was selected for the analysis.

\section{Results}

The hypothesised relationships between personal, community and civic variables were analysed using the AMOS 6 structural equation modelling program. The results are presented in Figures 2 and 3. All paths shown are significant. The results are based on data from 344 residents in Alaska and 512 in Oregon. Levels of preparedness, expressed in terms of the proportion of each sample that adopted each measure, are described in Table 1. Table 2 describes the percentage of people adopting specific preparedness measures in each location. The mean scores for the predictor variables are listed in Table 3. Preparedness measures were present at low-moderate levels. The goodness-of-fit statistics for the Alaska and Oregon models are described in Table 3.

In structural equation modelling, the objective is to find non-significant differences between the predicted and actual model. This is measured by the chi squared $\left(\chi^{2}\right)$ statistic. The nonsignificant values obtained here (Table 3) indicate that the actual model is a close fit to the hypothesised model. This is supported by the other fit indices (Table 3 ), all of which have values ranging from 0 (poor fit) to 1 (perfect fit).

The goodness-of-fit statistics and indices from both locations indicate that the data are a good fit for the hypothesised model (Arbuckle, 2006) and that the model can account for differences in observed levels of preparedness between people. Values of 0.90 and over 


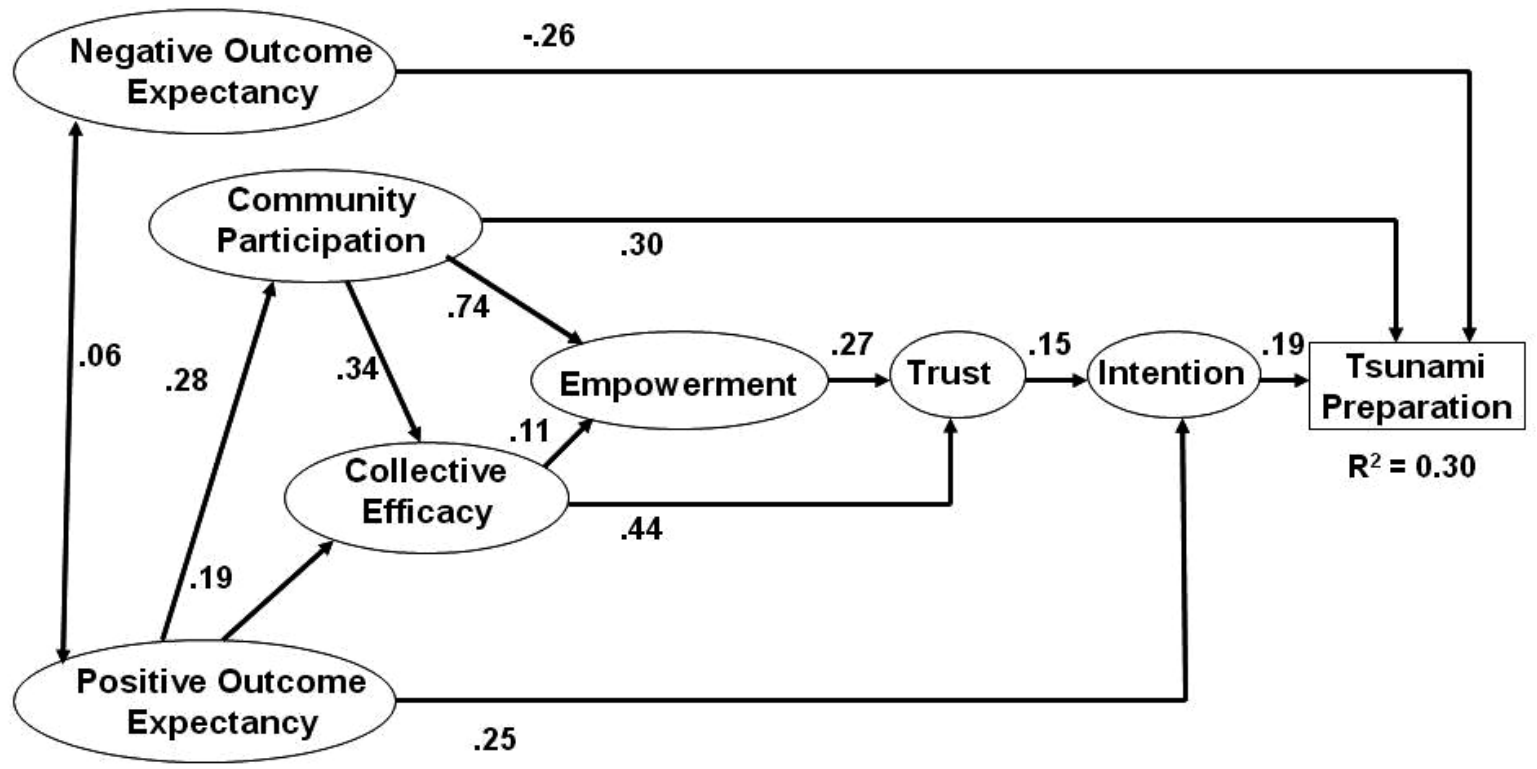

Figure 2

A summary of the structural equation analysis of the Alaska data illustrating the direction, sign and strength of relationships between variables

for the Goodness-of-Fit Index (GFI) indicate a good fit. Values of the Normed (NFI) and Comparative (CFI) Fit Indices above 0.95 are indicative of a good fit. RMSEA values of less than 0.05 are also indicative of a good fit. The model accounted for $30 \%$ and $26 \%$ of the variance $\left(\mathrm{R}^{2}\right)$ in levels of preparing in Alaska and Oregon respectively (Figures 2 and 3; Table 3).

\section{Discussion}

Overall, the fit indices (Table 3) indicate that the model is a good fit to the data from both locations. This, in conjunction with its ability to account for differences in levels of people's tsunami preparedness, means that the model can assist explaining differences in levels of hazard preparedness. This section commences with the implications of these findings for testing the hypotheses.

\section{Outcome Expectancy}

As hypothesised, an inverse relationship between negative outcome expectancy (NOE - people believe that the severity of tsunami consequences render personal actions futile) and preparing was found (Figures 2 and 3 ). This suggest that, for those holding NOE beliefs, information advising the adoption of preparation measures is more likely to be discounted or ignored because it will be inconsistent with people's existing belief that nothing can make a difference. These data (Table 2) suggest that there are issues of reliability to be dealt with for this variable. It is possible that the outcome expectancy variable is tapping into different processes. For example, it is possible to compare this with the construct of fatalism. The measure of outcome expectancy was intended to examine people's objective interpretation of the ability of a proposed action to increase their safety by protecting a person or a home from hazard consequences. This was informed by the fact that levels of sophistication in people's mental models of relationships between hazard characteristics and the efficacy of preparedness actions influences levels of preparedness. However, if this variable also picked up fatalistic beliefs, the conflation of different underlying mechanisms makes the interpretation of the data difficult. This suggests that future work will have to include a means of differentiating between the influence of fatalistic beliefs from the more objective cognitive process that is the intended target of the outcome expectancy construct.

Table 1

Means, Standard Deviations, Range and Cronbach's Alpha of Variables in the Model

\begin{tabular}{|c|c|c|c|c|c|c|}
\hline \multirow[b]{2}{*}{ Scale } & \multirow[b]{2}{*}{ Range } & \multirow[b]{2}{*}{$\alpha$} & \multicolumn{2}{|c|}{ Alaska } & \multicolumn{2}{|c|}{ Oregon } \\
\hline & & & Mean & SD & Mean & SD \\
\hline $\begin{array}{l}\text { Negative Outcome } \\
\text { Expectancy }\end{array}$ & $4-20$ & .69 & 6.99 & 3.10 & 7.61 & 3.17 \\
\hline $\begin{array}{l}\text { Positive Outcome } \\
\text { Expectancy }\end{array}$ & $4-20$ & .70 & 13.73 & 3.89 & 13.12 & 3.59 \\
\hline $\begin{array}{l}\text { Community } \\
\text { Participation }\end{array}$ & $5-20$ & .90 & 13.79 & 4.72 & 12.76 & 4.02 \\
\hline Collective Efficacy & $12-60$ & .95 & 37.25 & 12.35 & 34.54 & 12.25 \\
\hline Empowerment & $4-20$ & .89 & 10.52 & 3.88 & 9.12 & 3.79 \\
\hline Trust & $5-25$ & .95 & 20.69 & 7.62 & 14.12 & 5.54 \\
\hline Intentions & $5-15$ & .90 & 8.28 & 3.34 & 8.16 & 3.24 \\
\hline
\end{tabular}

Note: $(\mathrm{N}$ : Alaska $=344$; Oregon $=512$ ) 
Table 2

Frequency of Adoption of Emergency Response Items

\begin{tabular}{lcc}
\hline Emergency Response Item & Alaska & Oregon \\
\hline $\begin{array}{l}\text { Developed a family emergency response plan } \\
\text { Have a 3-day supply of non-perishable } \\
\text { food and water }\end{array}$ & $34 \%$ & $49 \%$ \\
$\begin{array}{l}\text { Have a back pack filled with supplies } \\
\text { ready to take with me }\end{array}$ & $42 \%$ & $52 \%$ \\
$\begin{array}{l}\text { Have a NOAA Weather Radio and } \\
\text { working batteries }\end{array}$ & $30 \%$ & $39 \%$ \\
$\begin{array}{l}\text { Prepared to respond to tsunamis in more } \\
\text { places than my home }\end{array}$ & $29 \%$ & $30 \%$ \\
\begin{tabular}{l} 
Participated in a tsunami evacuation drill \\
\hline
\end{tabular} & $28 \%$ & $40 \%$ \\
\hline
\end{tabular}

Note: $($ Alaska $=344 ;$ Oregon $=512)$.

While this possibility must remain tentative until further work is undertaken, the analyses suggest that $\mathrm{NOE}$ and POE are independent (Figure 2 and 3). If this is correct, this means that low preparedness within a community can result from two processes. One derives from the possibility that people who do not believe that preparing will be effective are less likely to act. The second describes those people who need additional guidance to facilitate their preparedness. This suggests that, when planning community hazard outreach programs, it will be important to distinguish between people who decide not to prepare (i.e., who form NOE beliefs) from those who accept a need to prepare but need more guidance in how to accomplish this. That is, strategies designed to guide preparedness will be ineffective for people holding NOE beliefs, and a separate strategy will be required to manage the latter.

\section{Community Characteristics}

The analyses support the hypothesis that community participation, collective efficacy, empowerment and trust mediated the relationship between POE and intentions and preparing. The analyses thus support the contention that social interaction with those that share similar beliefs and values (community participation) can influence preparing (Earle, 2004; Lion et al., 2002; Paton, in press). The analyses also support the argument that the level of planning and problem solving competence (collective efficacy) amongst community members makes an additional contribution to the process, as does empowerment (Figures 2 and 3). That is, community members and civic agencies play complementary roles in this process.

While not predicted, the modification indices for the analyses of both the Alaska and Oregon data identified the potential to improve model fit by including a direct relationship between collective efficacy and trust. One interpretation of this relationship is that, if having thought about their needs (e.g., the action of collective efficacy), people realise that public hazard education content meets their needs the necessity for any subsequent engagement (empowerment) with an expert source can be circumvented. Realising the value of existing information would increase trust in the source. This interpretation could also support the unexpected finding of a direct relationship between collective efficacy and intentions in the Oregon data (Figure 3). Until systematically tested, these interpretations remain tentative.

Overall, the findings suggest that, for some groups at least, facilitating preparedness may be less about agencies providing new or additional information, and more about developing community members' ability to render meaningful and utilise (e.g., by developing community member's problem solving and planning competencies) existing information. The importance of considering the relationship between the social context in which people live and work and preparedness reflects the fact that it represents the normal context in which information about hazard issues are received and interpreted. It makes people's perception of the quality of the relationship between themselves and civic sources of information an important facet of the preparedness process.

Empowerment mediated the relationship between community characteristics and competencies (participation and collective efficacy) and trust (Figures 2 and 3). This supports the argument that people's perception of the degree to which agencies empower them influences the level of trust in sources of information and the likelihood of preparing (Earle, 2004; Eng \& Parker, 1994; Paton et al., 2006; Siegrist \& Cvetkovich, 2000). The analyses reiterate the important role that engaging with community members, understanding their needs, and relating to them in ways that empower them has within a risk management strategy.

\section{Trust}

The final prediction, that trust mediated the relationship between empowerment and intentions, and subsequently actual preparation, was supported (Figures 2 and 3). Qualitative analysis of the focus group discussions in coastal communities in Oregon identified several factors

\section{Table 3}

Goodness of Fit Statistics and Indices

\begin{tabular}{lcc}
\hline Fit indices & Alaska & Oregon \\
\hline$\chi^{2}$ & 8.905 & 13.279 \\
$\mathrm{df}$ & 9 & 8 \\
$\mathrm{p}$ & 0.446 & 0.15 \\
RMSEA (90\%) & $0.000(0.000 .06)$ & $0.031(0.000 .062)$ \\
PCLOSE & .884 & .814 \\
$\mathrm{NFI}$ & 0.989 & 0.981 \\
CFI & 0.992 & 0.994 \\
GFI/AGFI & $0.99 / 0.974$ & $0.994 / 0.974$ \\
$\mathrm{R}^{2}$ & 0.30 & 0.26 \\
\hline
\end{tabular}




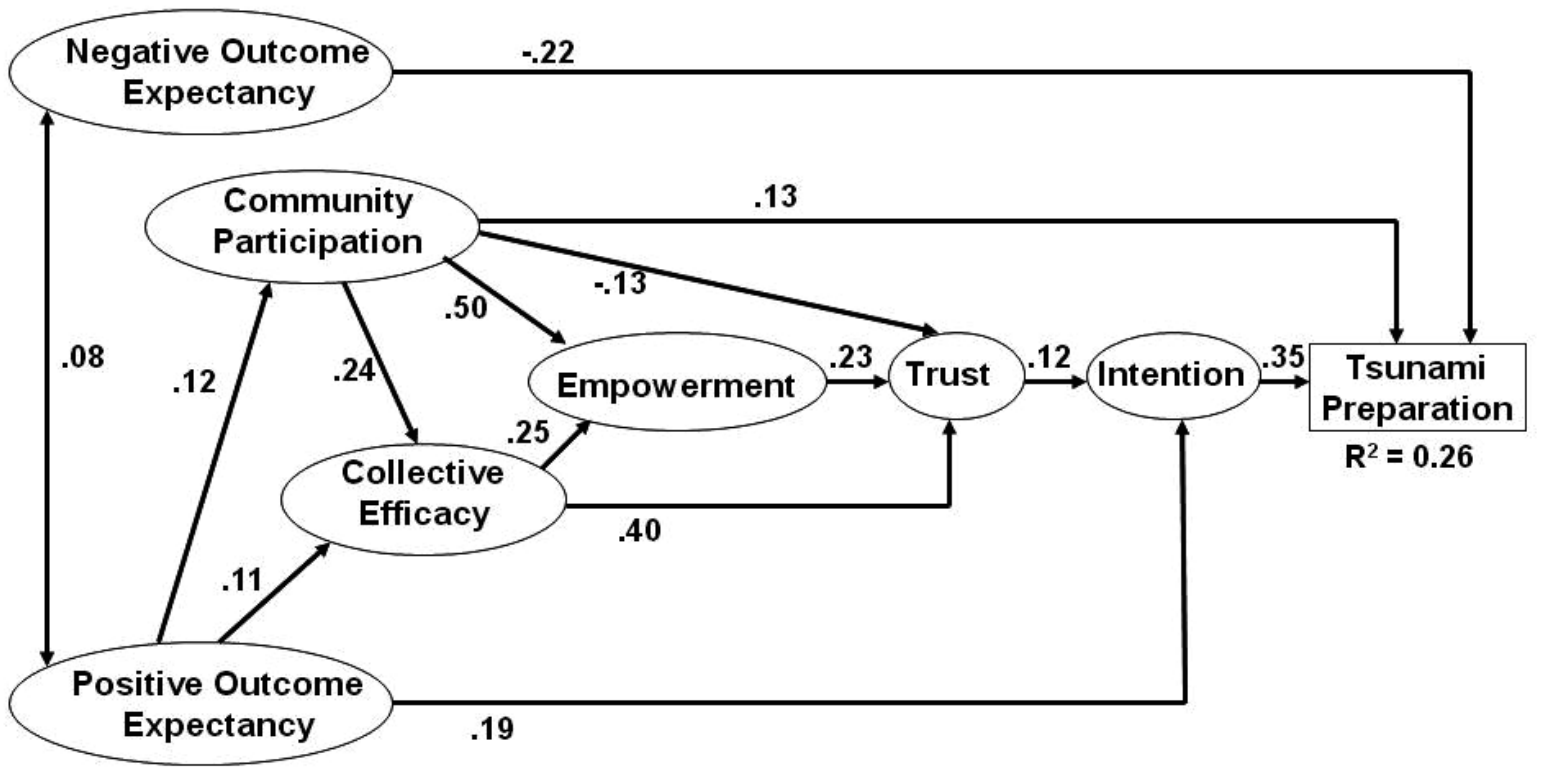

Figure 3

A summary of the structural equation analysis of the Oregon data illustrating the direction, sign and strength of relationships between variables

that inform understanding of factors that influence the quality of the social context in which people deal with the uncertainty associated with hazards.

People's feelings of empowerment were reduced by their perception that information was distributed infrequently and when it was, it was not in a format that stimulated people to act. For example, it was too general in nature and did not offer explicit information about the consequences people could have to contend with and the specific actions that would be required to mitigate these consequences. Empowerment, and feelings of trust, were adversely affected by the belief that civic agencies withheld information from people due to fear of it having a negative impact on their economy/business. That is, people felt that agencies put the economy ahead of the safety of citizens. These factors increased people's uncertainty, reduced their willingness to prepare, and increased their sense of apathy. That is, it increased the likelihood of their disengaging from the preparedness process. Not only did this reduce willingness to attend to public education information, it led to people raising issues about whether or not they would respond to warnings.

The latter issue regarding response to warnings stemmed from loss of trust in the process. For example, reduced trust in civic agencies resulted in people believing that they would not get timely warning or that the warning system was inadequate for the purpose. Distrust of civic agencies could also be traced to people's concerns regarding their belief that evacuation signs were not known very well, not specific enough, did not make sense to many residents, and were misleading (e.g. people did not feel that following these signs would lead them to safety, and following them could result in people going round in circles). Further, many residents believed that, if many people were following the signs simultaneously, the evacuation route would quickly become blocked. These examples provide some insights into how people's perceptions of the quality of the relationship between them and the civic sources they rely on to promote public safety can reduce the likelihood of preparing.

Overall, these relationships support the view that the more citizens are able to formulate their needs and perceive their needs as having been met through their relationship with civic agencies, the more likely they are to trust them and the information they provide, and to use the information to prepare to respond to tsunami. The analyses accounted for, on average, some $28 \%$ of the variance in levels of preparedness. From a practical perspective, it is important to have some means of gauging how good this level of prediction is.

Sheeran's (2002) meta-analysis of 422 studies concluded that accounting for $28 \%$ of the variance in behaviour would confer upon findings derived from using social cognitive models a medium to large effect size (Cohen, 1992). Given that the Alaska and Oregon data accounted for $30 \%$ and $26 \%$ of the variance in behaviour respectively, the model discussed here can be considered to provide a good level of prediction. This supports its use as a guide for planning community engagement processes that will encompass risk communication strategies intended to increase levels of tsunami preparedness. Furthermore, demonstrating that mainstream community processes and competencies influence hazard preparedness highlights the benefits that could accrue from integrating risk communication and community development processes rather than conceptualising risk communication 
as a stand-alone process delivered independently from other community initiatives (Paton, 2006).

The social context (community participation, collective efficacy, empowerment and trust) variables used here were tapping into pre-existing community competencies and patterns of community-agency relationships that reflect people's day-to-day experiences. Despite the fact that the processes these variables were tapping into were not specifically constituted to deal with hazard preparedness issues per se, they nonetheless made significant contributions to explaining differences in levels of preparedness. Emergency management agencies rarely actively harness these community processes and relationships (e.g., identifying the communities in their jurisdiction, providing information specifically tailored to needs generated by communities, and determining whether the competencies required to make effective use of information are present) to assist the attainment of their risk management objectives. Consequently, integrating risk management and community development activities in ways that specifically encourage discussion of hazard issues, develop community members' problem solving competencies, and encouraging agencies to engage with communities in ways that empower them could increase the likelihood of people preparing (Paton, 2006). The general nature of these variables examined here means that the social processes and competencies they are tapping into can influence preparedness for any hazard. While the possibility must remain tentative until more research is conducted, this suggests that the model has all-hazards capability.

It is important to recognise that this model is not intended to replace other models developed to explain hazard preparedness. Rather it is meant to complement them. For example, the protective action decision model (Lindell \& Perry, 2004) argues for a role for social context and information search processes in its conceptualisation of the preparedness process. The present study identifies specific candidates for the social context and information search components of the latter model. Future work could explore whether integrating the present model with the protective action decision model could enhance understanding of factors that predict hazard preparedness.

Finally, by distinguishing between intentions and actual preparedness behaviour, the model draws attention to the possible existence of several factors that influence whether intentions are converted into actual preparedness actions. A prominent constraint is peoples' beliefs regarding when a tsunami might occur (the further into the future this is believed to be, the less likely people are to convert intentions into action; Paton et al., 2005). In the present data, only $6 \%$ of respondents in Alaska and $9 \%$ in Oregon believed that a tsunami could occur within the next 12 months. This makes it important to frame messages that not only advise people think when rather than if a hazard will occur with they should be thinking sooner rather than later. Even if people are predisposed to prepare, a belief that a tsunami is unlikely to occur in the short term, means that while they may form preparedness intentions, they are unlikely to convert their intentions into actions. Similarly, the physical costs (e.g., time, money, need to work with others etc) associated with implementation can result in people failing to convert intentions into actions (Paton et al., 2005). Knowledge of these factors can inform the development of the content of additional information and engagement strategies.

\section{Conclusion}

For many people living in coastal communities in Pacific Rim countries, tsunamis represent a significant hazard. If a tsunami occurs, peoples' survival will be influenced by the degree to which they are prepared to respond. While developing the necessary knowledge, resources and plans in advance should be an imperative for all coastal communities, it is particularly important for those at risk from locally generated tsunami. Programs designed to facilitate this capability must accommodate the fact that community members and emergency management agencies influence peoples' preparedness decisions in ways that are independent of information provided per se. Certain characteristics of the social context in which people live their daily lives can influence levels of hazard preparedness. While people, communities and emergency management agencies make different contributions to this process, effective risk management will only ensue when their respective roles are integrated. The fact that the data furnished by the community and agency variables reflect mainstream experience means that they are applicable to any hazard.

Risk communication strategies must accommodate the role of the social context in determining the relevance and meaning of information and thus whether it is used, as intended, to facilitate preparedness. To do so, it is first important to encourage community members to discuss hazard issues, identify the resources and information they need to deal with the consequences a hazard would pose for them, and to ensure that communities possess the competencies required to use information to plan how best to act. Second, it is important to ensure that the community-agency relationship is complementary and empowering. Finally, additional work is required to understand the factors that influence the conversion of intentions into actual preparedness behaviour. The potential for this work to complement other models in ways that might advance understanding of hazard preparedness by developing more comprehensive models was also acknowledged.

In common with most survey data, the findings presented here should be considered tentative because the characteristics and likely actions of those who failed to respond (the average rate of return was 29\%) to the survey remain a subject about whom one can 
only speculate. However, the fact that data from respondents who were disinclined to prepare was collected means that one group that might be expected not to respond to a survey about preparedness (i.e., those who do not believe there is any point) were represented to some extent. Another limitation relates to the fact that the linear process depicted here does not accommodate the feedback and discussion processes likely to occur between people and that will progressively influence (both positively and negatively) their preparedness decisions over time.

By demonstrating the model is a valid and reliable predictor of preparedness decisions, the analyses presented here provide a sound foundation for future more comprehensive, longitudinal analyses. In conclusion, the work presented here suggests that, when public hazard education programs are developed in ways that ensure that communities and emergency management agencies play complementary roles in the risk management process, community member's levels of trust, satisfaction with communication, willingness to take responsibility for their own safety, and commitment to prepare for hazard consequences, will increase.

\section{Acknowledgments}

Funding for this project was provided by NSF Award \# 0527387

\section{References}

Arbuckle, J.L. (2006). Amos 6.0 User's Guide. Chicago IL:.SPSS,

Bandura, A. (1997). Self-efficacy and agency of change. New York: Raven Press.

Bennett, P., \& Murphy, S. (1997). Psychology and health promotion. Buckingham: Open University Press.

Cohen, J. (1992). A power primer. Psychological Bulletin, 112, 155-159.

Dillon, J., \& Phillips, M. (2001). Social capital. Perth, Western Australia: Curtin University.

Duncan, T.E., Duncan, S.C., Okut, H., Strycker, L.A., \& HixSmall, H. (2003). A multilevel contextual model of neighbourhood collective efficacy. American Journal of Community Psychology, 32, 245-252.

Duval, T.S., \& Mulilis, J.P. (1999). A Person-Relative-to-Event (PrE) Approach to negative threat appeals and earthquake preparedness: A field study. Journal of Applied Social Psychology, 29, 495-516.

Earle, T.C. (2004). Thinking aloud about trust: A protocol analysis of trust in risk management. Risk Analysis, 24, 169-183.

Earle, T.C., \& Cvetkovich, G.T. (1995). Social trust: Towards a cosmopolitan society. Westport, CT: Praeger.

Eng, E., \& Parker, E. (1994). Measuring community competence in the Mississippi Delta: The interface between program evaluation and empowerment, Health Education Quarterly, 21, 199-220.
General Accountability Office (GAO) (2006). U.S. Tsunami preparedness. United States Government Accountability Office Report, GAO-06-519. Washington, DC: General Accountability Office.

Horikawa, K., \& Shuto, N. (1983). Tsunami disasters and protective measures in Japan. In K. Iida \& T. Iwsaki (Eds.), Tsunamis: Their science and engineering (pp. 9-22). Tokyo: Terra Scientific Publishing Co.

Kee, H., \& Knox, R.T. (1970). Conceptual and methodological considerations in the study of trust and suspicion. Journal of Conflict Resolution, 14, 357-365.

Lindell, M.K., \& Perry, R.W. (2004). Communicating environmental risk in multiethnic communities. Thousand Oaks CA: Sage.

Lindell, M.K., \& Whitney, D.J. (2000). Correlates of household seismic hazard adjustment adoption. Risk Analysis, 20, 13-25.

Lion, R., Meertens, R.M., \& Bot, I. (2002). Priorities in information desire about unknown risks. Risk Analysis, 22, 765-776.

Marris, C., Langford, I.H., \& O'Riordan, T. (1998). A quantitative test of the cultural theory of risk perceptions: Comparisons with the psychometric paradigm. Risk Analysis, 18, 635-647.

Mayer, R.C., Davis, J.H., \& Schoorman, F.D. (1995). An integrative model of organizational trust. Academy of Management Review, 20, 709-734.

McAllister, D.J. (1995). Affect- and cognition-based trust as foundations for interpersonal cooperation in organizations. Academy of Management Journal, 38, 24-59.

Mileti, D.S., \& Sorensen, J.H. (1987). Why people take precautions against natural disasters. In N. Weinstein (Ed.), Taking care: Why people take precautions (pp. 296-320). New York: ??Name of publisher.

Paton, D. (2008). Risk communication and natural hazard mitigation: How trust influences its effectiveness. International Journal of Global Environmental Issues, 8, 2-16.

Paton, D. (2009). Community sustainability and natural hazard resilience: All-hazard and cross-cultural issues in disaster resilience. The International Journal of Environmental, Cultural, Economic \& Social Sustainability, $5,345-356$.

Paton, D. (2007). Measuring and monitoring resilience in Auckland, GNS Science Report 2007/18. 88 p.

Paton, D., \& Bishop B. (1996). Disasters and communities: Promoting psychosocial well-being. In D. Paton \& N. Long (Eds.), Psychological aspects of disaster: Impact, coping, and intervention. Palmerston North, New Zealand: Dunmore Press.

Paton, D., Smith, L.M., \& Johnston, D. (2005). When good intentions turn bad: Promoting natural hazard preparedness. Australian Journal of Emergency Management, 20, 25-30.

Poortinga, W., \& Pidgeon, N.F. (2004). Trust, the asymmetry principle, and the role of prior beliefs. Risk Analysis, 24, 1475-1486.

Rippl, S. (2002). Cultural theory and risk perception: A proposal for a better measurement. Journal of Risk Research, 5, 147-165. 
Siegrist, M., \& Cvetkovich, G. (2000). Perception of hazards: The role of social trust and knowledge. Risk Analysis 20, 713-719.

Sheeran, P. (2002). Intention-behaviour relations: A conceptual and empirical review. In W. Stroebe \& M. Hewstone (Eds.), European review of social psychology (pp. 1-36). Chichester, England : Wiley.

Speer, P.W., \& Peterson, N.A. (2000). Psychometric properties of an empowerment scale: Testing cognitive, emotional and behavioural domains. Social Work Research, 24, 109-118.

Weigel, R.L. (2006). Tsunami information sources: Part 2 (Technical Report UCB/HEL 2006-1). Berkeley, CA: Department of Civil and Environmental Engineering, University of California.

Zaccaro, S.J., Blair, V., Peterson, C., \& Zazanis, M. (1995). Collective efficacy. In: Maddux, J.E. (Ed.), Self efficacy, adaptation, and adjustment: Theory, research, and application (pp. 305-328). New York: Plenum Press. 